\title{
Leisure athletes at risk of medical complications: outcomes of pre- participation screening among 15,778 endurance runners - SAFER VII
}

Karen Schwabe, Martin Schwellnus, Sonja Swanevelder, Esme Jordaan, Wayne Derman and Andrew Bosch

\begin{abstract}
Objective: International guidelines for pre-participation screening of masters/leisure athletes to identify those that require medical assessment exist, but have not been implemented in mass-community based sports events. We determined the prevalence of runners who, according to these guidelines, would require a medical assessment before participating in a distance running event.

Methods: Participants of the 2012 Two Oceans races (21.1 and $56 \mathrm{~km})$ in South Africa $(\mathrm{n}=$ 15,778) completed an online pre-race medical screening questionnaire using European preparticipation screening guidelines. We determined the prevalence of runners that would require a pre-race medical assessment, based on risk factors, symptoms, and disease.

Results: The pre-participation "self assessment of risk" screening identified 4,941 runners (31.3\%; 95\% CI 30.6-32.0) that would need to undergo a full pre-participation medical assessment prior to running, if the current pre-participation screening guidelines are applied. Although musculoskeletal complaints and prescription medication use were the main triggers for a medical assessment, $16.8 \%(n=2657)$ runners should undergo medical evaluation for suspected cardiac disease based on the questionnaire results: $3.4 \%(n=538)$ reporting existing CVD (very high risk) and $13.4 \%(\mathrm{n}=2119)$ reporting multiple CVD risk factors (high risk). Other possible risk factors were reported as follows: history of chronic diseases (respiratory $=13.1 \%$, gastro-intestinal $=4.3 \%$, nervous system $=3.8 \%$, metabolic/endocrine $=3.5 \%$, allergies $=13.9 \%$; chronic prescription medication $=14.8 \%$, used medication before or during races $=15.6 \%$; past history of collapse during a race $=$ $1.4 \%$.

Conclusions: Current guidelines identified that $>30 \%$ runners would require a full medical assessment before race participation - mainly linked to runners reporting musculoskeletal conditions. We suggest a revision of guidelines and propose that pre-race screening should be considered to identify runners with a "very high," "high," and "intermediate risk" for medical complications during exercise. Pre-race screening and educational intervention could be implemented to reduce medical complications during exercise.
\end{abstract}




\section{Introduction}

Regular participation in physical activity ( $>150 \mathrm{~min}$ per week at moderate- to highintensity) has numerous health benefits, including the prevention and management of chronic non-communicable disease [1,2]. Recreational running has become an increasingly popular form of regular physical activity and participation in community based recreational distance running events such as the $21.1 \mathrm{~km}$ (half-marathon), marathon $(42.2 \mathrm{~km}$ ), and ultra-marathon races has concomitantly increased [3]. Annual reports from Running USA (http://www.runningusa.org/annual-reports - accessed on 1 March 2017) show an increase of $>12$-fold in overall participation in marathon runners since 1976, specifically increases in participation in the older age groups ( $>40$ years).

While the health benefits of exercise are numerous, medical complications during moderate- to high-intensity vigorous physical activity, such as distance running, in a variety of organ systems have been described [4-6] Acute cardiac events, including myocardial infarction and sudden death, are described in both younger and older runners [7-10]. Determining the risk of sudden death during exercise, in particular during distance running events such as the half-marathon $(21.1 \mathrm{~km})$ and marathon $(42.2 \mathrm{~km})[11,12]$ using pre-screening tests and detailed diagnostics (ECG) has been proposed $[5-8,13-16]$.

Pre-participation screening for CVD is routinely recommended and performed for younger competitive elite athletes across the world [17-22] but not in leisure athletes older than 35 years, despite an exponentially higher risk of acute cardiac episodes in these older athletes due to increased incidences of atherosclerotic coronary artery disease [23]. Preparticipation screening guidelines for masters ( $\geq 50$ years) and leisure athletes have been proposed by the American Heart Association (AHA) [24], American College of Sports Medicine (ACSM) [25], Canadian Physical Activity Readiness Questionnaire (PAR-Q+), and the Physical Activity Readiness Medical Examination (ePARMed-X+) [26], and the European Society of Cardiology (ESC) together with the European Association of Cardiovascular Prevention and Rehabilitation (EACPR) [27,28].

These guidelines "provide a pragmatic and practical approach to identifying higher-risk individuals to minimize the risk of sudden cardiac death (SCD)" [28]. The screening process begins with a "self-assessment of risk" which is followed up by medical intervention for identified high-risk athletes. The "self-assessment of risk," recommended by the ESC and EACPR, can be conducted by the individual athlete or by non-physician health professionals [28] and is based on the recommended AHA/American College of Sports Medicine (ACSM) pre-participation screening questionnaire for individuals at Health/Fitness facilities [29]. The initial "self-assessment of risk." In Section 1, health information related to known cardiovascular disease, cardiovascular symptoms, medication use, and other health issues is collected and in Section 2, known risk factors for cardiovascular disease are identified. If the respondents provide one positive response to any question related to Section 1 (health information), or if 2 or more risk factors are identified in Section 2, they are advised to undergo a thorough medical assessment by a qualified physician before participating in moderate- to 
high-intensity exercise, such as distance running [28]. More recently, a task force from the ACSM published revised screening guidelines, and in these new guidelines, risk factors for CVD (Section 2) were omitted [25].

We are only aware of one study where the ESC/EACPR screening guidelines were applied to adult participants > 40 years of age [30]. In this study, based on "self assessment of risk," approximately $95 \%$ of women and $93.5 \%$ of men were advised to consult a physician before embarking on exercise [30]. We are not aware of any studies describing the outcome of the ESC/EACPR screening guidelines when applied to participants in mass communitybased endurance events.

In the first of our SAFER (Strategies to reduce Adverse medical events For the ExerciseR) studies [5,31-33] we report a high risk of serious of cardiac and non-cardiac medical complications at endurance events [5].

In this study, as part of the ongoing SAFER initiative, we wanted to determine the prevalence of runners who, according to the current European guidelines for "risk self assessment," would be at higher risk of acute cardiac medical complications and be required to undergo a medical assessment before participating in the Two Oceans $21.1 \mathrm{~km}$ or $56 \mathrm{~km}$ races. Furthermore, we wanted to determine the factors in the current guidelines that trigger this recommendation. As a secondary aim, we also explore the prevalence of other potential "risk factors" associated with serious non-cardiac medical complications such as other chronic systemic diseases, use of medication, and previous collapse during exercise [6] that are not currently routinely included in international pre-exercise screening guidelines.

\section{Methods}

\section{Setting}

The Old Mutual Two Oceans Marathon races are mass community-based running events that take place annually during late summer in Cape Town, South Africa. Approximately 25,000 runners are attracted to the two main events, the $21.1 \mathrm{~km}$ (half-marathon) and the $56 \mathrm{~km}$ (ultra-marathon) races every year. Males and females of all ages older than 16 years can enter, and entries to the $21.1 \mathrm{~km}$ race are open to novice runners and require no qualifying time. Entries for the $56 \mathrm{~km}$ race requires completion of any one of the following qualifying times: a standard $42.2 \mathrm{~km}$ marathon in $<5 \mathrm{~h}, 50 \mathrm{~km}$ in $<6.5 \mathrm{~h}$, $56 \mathrm{~km}$ in $<7 \mathrm{~h}, 90 \mathrm{~km}$ in $<12 \mathrm{~h}$, or a $100 \mathrm{~km}$ race in $<13.5 \mathrm{~h}$. A high rate of acute medical complications, including sudden death, in the runners competing in the old Mutual Two Oceans Marathon races [5,32] precipitated the design and implementation of an online pre-race medical screening program for all race entrants in 2012.

\section{Participants}

In 2012, all race entrants $(n=25,455)$ completed a pre-race medical screening questionnaire as part of the online registration process. Of these, 15,778 (62.0\% of all race entrants) gave informed consent that their personalized medical data could be used for 
research purposes and these runners were designated as participants in this study. The study participants were representative (for gender, age, and race type) of all race entrants (Table 1).

The 15,778 study participants consisted of 8,916 (56.5\%) male and 6,862 (43.5\%) female entrants. In the study group, compared to all entrants, there were equal proportions of athletes in the $21.1 \mathrm{~km}$ and $56 \mathrm{~km}$ races and in males vs. females. In the age categories there were equal proportions of runners in the age group 31 to 39 years old (All = $31.7 \%$, Study group $=28.5 \%$ ), but there was a large proportion of runners in the younger $(<30$ years) $($ All $=29.4 \%$, Study group $=31.4 \%)$ and older $(>40$ years $)($ All $=$ $38.9 \%$, Study group $=40.1 \%)$ age groups $($ Table 1$)$.

Table 1 . The profile by race type, sex, and age groups of all race entrants and runners who participated in this study.

\begin{tabular}{|c|c|c|c|c|c|}
\hline & & \multicolumn{2}{|c|}{$\begin{array}{l}\text { All race entrants } \\
(\mathrm{n}=25455)\end{array}$} & \multicolumn{2}{|c|}{$\begin{array}{l}\text { Runners } \\
\text { participating in this } \\
\text { study }(\mathrm{n}=15778)\end{array}$} \\
\hline & & $\mathrm{N}$ & $\%$ & $\mathrm{~N}$ & $\%$ \\
\hline \multirow[t]{2}{*}{ Race type } & $21.1 \mathrm{~km}$ & 16,284 & 64.0 & 10,786 & 68.4 \\
\hline & 56 km & 9,171 & 36.0 & 4,992 & 31.6 \\
\hline \multirow[t]{2}{*}{ Gender } & Males & 14,775 & 58.0 & 8,916 & 56.5 \\
\hline & Females & 10,680 & 42.0 & 6,862 & 43.5 \\
\hline \multirow[t]{3}{*}{ Age groups } & $\leq 30$ years & 7,471 & 29.4 & 4,951 & $31.4^{*}$ \\
\hline & $31-39$ years & 8,074 & 31.7 & 4,499 & 28.5 \\
\hline & $\geq 40$ years & 9,910 & 38.9 & 6,328 & $40.1^{*}$ \\
\hline \multirow[t]{2}{*}{ Males x Age } & Males $<45$ years & 21,150 & 83.1 & 13,304 & 84.3 \\
\hline & Males > 45 years & 4,305 & 16.9 & 2,474 & $15.7^{*}$ \\
\hline \multirow[t]{2}{*}{ Females x Age } & Females $<55$ years & 25,013 & 98.3 & 15,509 & 98.3 \\
\hline & Females $>55$ years & 442 & 1.7 & 269 & 1.7 \\
\hline
\end{tabular}

*: Significantly different from all race entrants $(p<0.05)$

For purposes of conducting research on this population, permission to investigate the prevalence of risk factors for cardiovascular disease, existing medical diseases, allergies, medication use, and injury history during endurance running in the Two Oceans races was obtained from the Research Ethics Committee of the University of Cape Town (REC 009/ 2011) (REC 030/2013) and the Research Ethics Committee of the University of Pretoria (REC 433/2015).

\section{Online pre-race medical screening questionnaire}

An online pre-race medical screening questionnaire (OPRMSQ) or "self-assessment of risk" was developed to identify runners that are at possible increased risk of acute 
medical complications during moderate-to high intensity exercise such as a distance running race [6]. The questions were based on the ESC and the EACPR guidelines for pre-exercise screening [28] with additional questions on general prescription medication use, including medication use during racing and a past history of collapse during racing.

The main elements of the questionnaire (Table 2) consisted of 2 injury-related questions (muscle cramping and running injuries) and 13 questions that included the following categories of medical history: cardiovascular disease (CVD), symptoms of CVD, risk factors for CVD, other chronic disease (respiratory disease, metabolic or hormonal disease, gastrointestinal disease, nervous system disease, renal or bladder disease, hematological or immune system disease, cancer, allergies). With the exception of a question regarding pregnancy, the OPRMSQ included all the questions in the AHA/ ACSM pre-participation screening questionnaire for individuals at Health/Fitness facilities [29], as recommended by the ESC and the EACPR for the pre-participation screening of leisure athletes engaging in moderate- to high-intensity exercise [27].

\section{Statistical analysis}

All data from the runner and medical questionnaire database were analyzed using the SAS Enterprise Guide (V6.1) statistical package (SAS Institute Inc., Cary, North Carolina, USA). Crude numbers, prevalence, and 95\% confidence intervals were reported throughout.

\section{Results}

Prevalence of risk factors for cardiovascular disease (CVD), symptoms of CVD, and existing CVD in runners

The prevalence of existing CVD, symptoms of CVD, and risk factors for cardiovascular disease (CVD) in runners is depicted in Table 3. In this group of distance runners $(\mathrm{n}=$ 15,778), 360 (2.3\%; 95\% CI 2.1-2.5) reported suffering from existing CVD. The most common reported cardiovascular condition in runners with existing CVD $(\mathrm{n}=360)$ was a heart murmur (0.6\%; 95\% CI 0.5-0.7), followed by known coronary artery disease (0.5\%; 95\% CI 0.4-0.6), and arrhythmia (0.4\%; 95\% CI 0.3-0.6) (Table 2). Other reported specific CVDs were a history of rheumatic fever (0.2\%; 95\% CI 0.1-0.3), and myocardial infarction (0.2\%; 95\% CI 0.1-0.3). In this category of "other," less than $0.4 \%$ of runners reported existing CVD.

Of the runners surveyed, 284 (1.8\%; 95\% CI 1.6-2.0) reported at least one symptom of CVD. The more common specific symptoms of CVD in runners were painful calves during walking (0.5\%; 95\% CI 0.4-0.6), a history of dizziness or fainting during exercise (0.4\%; 95\% CI 0.3-0.5), pain in the neck, jaw or arms (0.3\%; 95\% CI 0.2-0.4), swollen ankles (0.3\%; 95\% CI 0.2-0.3), shortness of breath with mild exercise (0.3\%; 95\% CI 0.2-0.3), and chest pain (0.20\%; 95\% CI 0.1-0.2) (Table 2). Other possible symptoms of CVD (water retention, palpitations, chronic cough) were reported by $\leq 0.2 \%$ of runners. The total number of runners who reported either known CVD or symptoms suggestive of CVD was 538 , which is $3.4 \%$ of all the runners. 
Medical screening questionnaire - self-assessment of risk*

(1) Have you ever suffered from any heart or blood vessel conditions including heart attack, undiagnosed chest pain, coronary artery bypass operation, angioplasty (balloon), heart failure, heart transplant, cardiac arrhythmia (abnormal heart beat), rheumatic fever, heart murmur, cardiomyopathy, myocarditis, use of a pacemaker, or inherited heart defect?

(2) Do you currently suffer from any symptoms of heart or blood vessel disease, including any of the following: shortness of breath when sitting or lying down, shortness of breath with mild exercise, waking up with shortness of breath at night, palpitations that make you dizzy, chest pain when sitting or performing exercise or when you are emotionally stressed, pain (or discomfort) in the neck jaw arms at rest or during exercise, dizziness during exercise or fainting spells)?

(3) Are you aware or have you ever been diagnosed with any risk factors for heart or blood vessel disease including high blood cholesterol, a family member with heart disease, cigarette smoking, lack of physical activity, high blood pressure, being overweight, or having diabetes mellitus (sugar sickness)?

(4) Do you currently suffer from any metabolic or hormonal disease including diabetes mellitus thyroid gland disorders hypoglycemia (low blood sugar) hyperglycemia (high blood sugar), or heat intolerance?

(5) Do you suffer from any respiratory (lung) disease including asthma, emphysema (COPD), wheezing, cough, postnasal drip, hay fever, or repeated flu like illness?

(6) Do you suffer from any gastrointestinal disease including heartbum, nausea, vomiting, abdominal pain, weight loss or gain (> $5 \mathrm{~kg}$ ), a change in bowel habits, chronic diarrhea, blood in the stools, or past history of liver or gallbladder disease?

(7) Do you suffer from any diseases of the nervous system including past history of stroke or transient ischemic attack (TIA), frequent headaches, epilepsy, depression, anxiety attacks, muscle weakness, nerve tingling, loss of sensation, or chronic fatigue?

(8) Do you suffer from any disease of the kidney or bladder including past history of kidney or bladder disease, blood in the urine, loin pain, kidney stones, frequent urination, or burning during urination?

(9) Do you suffer from any disease of the blood or immune system including anemia, recurrent infections, HIV/AIDS, leukemia, or are you using any immunosuppressive medication?

(10) Do you suffer from any growths or cancer, including a past history of cancer?

(11) Do you suffer from any allergies including a past history of allergies, to medication, plant material, or animal material?

(12) At the moment do you use any prescribed medication on a daily weekly or monthly basis to treat chronic (long-term) medical conditions or injuries?

(13) Have you ever collapsed (fell down not because of an accident needing medical attention) during at the finish or after a race or training session?

(14) Do you, or did you suffer from any symptoms of a running injury (muscles tendons bones ligaments or joints) in the last 12 months?

(15) Have you ever in your running career suffered from muscle cramping (painful spontaneous sustained spasm of a muscle) during or immediately (within $6 \mathrm{~h}$ ) after running (in training or competition)?

*: Once a participant answered "yes" to any of the main screening questions, further details were obtained using "dropdown" boxes with additional questions 
Table 3. The prevalence of existing cardiovascular disease (CVD), history of any symptoms of CVD, or any risk factor for CVD in all runners $(n=15778)(\%$ runners; $95 \% \mathrm{Cl}$ ).

\begin{tabular}{|c|c|c|c|c|}
\hline \multirow[b]{3}{*}{ Any existing CVD } & \multicolumn{4}{|c|}{ All runners $(n=15778)$} \\
\hline & \multirow{2}{*}{$\frac{n}{360}$} & \multirow{2}{*}{$\frac{\%}{2.3}$} & \multicolumn{2}{|c|}{$95 \% \mathrm{Cl}$} \\
\hline & & & 2.1 & 2.5 \\
\hline Myocardial infarction (MI) & 31 & 0.2 & 0.1 & 0.3 \\
\hline Angina & 22 & 0.1 & 0.1 & 0.2 \\
\hline Coronary artery bypass graft (CABG) & 19 & 0.1 & 0.1 & 0.2 \\
\hline Angioplasty - no stent & 10 & 0.1 & 0.0 & 0.1 \\
\hline Angioplasty - with stent & 31 & 0.2 & 0.1 & 0.3 \\
\hline Coronary artery disease (CAD) & 80 & 0.5 & 0.4 & 0.6 \\
\hline Heart failure & 1 & 0.01 & 0.0 & 0.0 \\
\hline Heart transplant & 0 & 0.0 & - & - \\
\hline Angioplasty with/without stent & 40 & 0.3 & 0.2 & 0.3 \\
\hline Heart failure/transplant & 1 & 0.01 & 0.0 & 0.0 \\
\hline Arrhythmia & 70 & 0.4 & 0.3 & 0.6 \\
\hline Rheumatic fever & 33 & 0.2 & 0.1 & 0.3 \\
\hline Heart murmur & 98 & 0.6 & 0.5 & 0.7 \\
\hline Pacemaker & 6 & 0.04 & 0.0 & 0.1 \\
\hline Inherited cardiac condition & 11 & 0.1 & 0.0 & 0.1 \\
\hline Other & 64 & 0.4 & 0.3 & 0.5 \\
\hline Any history of symptoms of CVD & 284 & 1.8 & 1.6 & 2.0 \\
\hline Swollen ankles & 40 & 0.3 & 0.2 & 0.3 \\
\hline Water retention & 25 & 0.2 & 0.1 & 0.2 \\
\hline Shortness of breath sit/lying & 8 & 0.1 & 0.0 & 0.1 \\
\hline Short breath mild exercise & 39 & 0.3 & 0.2 & 0.3 \\
\hline Waking up short breath & 4 & 0.03 & 0.0 & 0.1 \\
\hline Palpitations/no dizziness & 22 & 0.1 & 0.1 & 0.2 \\
\hline Palpitations/dizziness & 4 & 0.03 & 0.0 & 0.1 \\
\hline Chest pain sitting & 4 & 0.03 & 0.0 & 0.1 \\
\hline Chest pain/exercise & 8 & 0.1 & 0.0 & 0.1 \\
\hline Chest pain normal & 20 & 0.1 & 0.1 & 0.2 \\
\hline Pain in the neck, jaw or arms at rest & 52 & 0.3 & 0.2 & 0.4 \\
\hline Chest pain & 32 & 0.2 & 0.1 & 0.3 \\
\hline Dizziness during exercise & 46 & 0.3 & 0.2 & 0.4 \\
\hline Fainting & 23 & 0.2 & 0.1 & 0.2 \\
\hline Dizziness/fainting & 61 & 0.4 & 0.3 & 0.5 \\
\hline Chronic cough & 21 & 0.1 & 0.1 & 0.2 \\
\hline Painful calves during walking & 72 & 0.5 & 0.4 & 0.6 \\
\hline Any risk factors for CVD & 2544 & 16.1 & 15.5 & 16.7 \\
\hline High blood pressure & 696 & 4.4 & 4.1 & 4.7 \\
\hline High Blood cholesterol concentration & 921 & 5.8 & 5.5 & 6.2 \\
\hline Cigarette smoking & 335 & 2.1 & 1.9 & 2.4 \\
\hline Overweight & 186 & 1.2 & 1.0 & 1.4 \\
\hline Diabetes mellitus & 150 & 1.0 & 0.8 & 1.1 \\
\hline Family history of heart disease & 688 & 4.4 & 4.0 & 4.7 \\
\hline Males $>45$ years & 2474 & 15.7 & 15.1 & 16.3 \\
\hline Females $>55$ years & 269 & 1.7 & 1.5 & 1.9 \\
\hline
\end{tabular}

*: Prevalence $(\%)$ in all runners 
In this group of runners, 2,544 (16.1\%; 95\% CI 15.5-16.7) reported at least one risk factor for CVD. The most common risk factor for CVD in runners was a combination of male and age > 45 years $(15.7 \%$; 95\% CI 15.1-16.3). Other common specific risk factors for CVD included high blood cholesterol concentration (5.8\%; 95\% CI 5.5-6.2), high blood pressure (4.4\%; 95\% CI 4.1-4.7), and a family history of heart disease (4.4\%; 95\% CI 4.0-4.7). Less than $4 \%$ of runners reporting other CVD risk factors such as smoking, being overweight, or suffering from diabetes mellitus (Table 2). The total number of runners who reported more than one risk factor for CVD was 2,119, which is $13.4 \%$ of all the runners.

\section{Prevalence of chronic diseases in other organ systems in runners}

In this study, 2061 runners (13.1\%; 95\% CI 12.5-13.6) reported a history of respiratory disease. The more common specific respiratory diseases were reported as follows: allergies/hay fever (8.6\%; 95\% CI 8.2-9.1) and asthma (5.9\%; 95\% CI 5.5- 6.3) (Table 4). Runners also reported a history of other chronic disease, including GIT disease (4.3\%; 95\% CI 4.0-4.7, $\mathrm{n}=683$ ), metabolic and endocrine disease (3.5\%; 95\% CI 3.2-3.8, $\mathrm{n}=552)$, and kidney or bladder disease (2.3\%; 95\% CI 2.0- 2.5, $\mathrm{n}=358)$. Furthermore, $13.9 \%$ (95\% CI 13.3-14.4, $\mathrm{n}=2189$ ) runners reported a history of any allergy, while $14.8 \%$ (95\% CI $14.2-15.3, \mathrm{n}=2333$ ) runners reported the use of chronic prescription medication.

\section{Prevalence of medication use by runners one week before, or during racing}

In this group of runners, 2,459 runners (15.6\%; 95\% CI 15.0- 16.2) reported using medication to treat injuries either before or during races. In the week before a race, runners commonly used anti-inflammatory medication (12.8\%; 95\% CI 12.3-13.3), specifically non-steroidal anti-inflammatory medications (NSAIDs) (9.1\%; 95\% CI 8.7-9.6), while $3.9 \%$ (95\% CI 3.6-4.2) of runners reported using paracetamol, and 1.6\% (95\% CI 1.4-1.8) used cortisone in the week prior to a race (Table 5).

During the race, the most common reported specific medication used was also antiinflammatory medication $(7.8 \%, 95 \%$ CI $7.4-8.2)$, more specifically, the NSAIDs $(4.9 \%$; 95\% CI 4.6-5.3). In addition, 3.1\% (95\% CI 2.8-3.3) of the runners used paracetamol during a race, followed by the use of other analgesics (1.8\%; 95\% CI 1.6-2.0) (Table 5).

\section{Prevalence of past history of collapse during training or racing in runners}

In this group of runners, $196(89.1 \%, 95 \%$ CI: 84.9 - 93.2) reported a history of collapse either during training or during a race.

The total number of runners who reported any known underlying chronic diseases, and/or medication use, and/or a past history of collapse was 7,738, which is $49.1 \%$ of all runners. 
Table 4. The prevalence of runners (\% runners; $95 \% \mathrm{Cl}$ ) with disease in other organ systems, medication use, and history of collapse $(n=15778)$.

\begin{tabular}{lcrrr}
\hline & \multicolumn{4}{c}{ All runners (n=15 778) } \\
\cline { 2 - 5 } Chronic disease/medication use & $\mathrm{n}$ & $\%^{*}$ & $95 \% \mathrm{Cl}$ \\
\hline History of respiratory disease & 2,061 & 13.1 & 12.5 & 13.6 \\
Asthma & 928 & 5.9 & 5.5 & 6.3 \\
Allergies/hay fever & 1,359 & 8.6 & 8.2 & 9.1 \\
Recurrent respiratory tract infections & 76 & 0.5 & 0.4 & 0.6 \\
Previous lung complaints & 31 & 0.2 & 0.1 & 0.3 \\
COPD & 3 & - & - & - \\
Interstitial lung disease & 1 & - & - & - \\
Cystic fibrosis & 2 & - & - & - \\
Other respiratory complaints & 20 & - & - & - \\
History of metabolic or endocrine disease & 552 & 3.5 & 3.2 & 3.8 \\
History of gastrointestinal (GIT) disease & 683 & 4.3 & 4.0 & 4.7 \\
History of nervous system disease & 593 & 3.8 & 3.5 & 4.1 \\
History of kidney or bladder disease & 358 & 2.3 & 2.0 & 2.5 \\
History of blood or immune system disease & 138 & 0.9 & 0.7 & 1.0 \\
History of growths/cancers & 298 & 1.9 & 1.7 & 2.1 \\
History of any allergy & 2,189 & 13.9 & 13.3 & 14.4 \\
History of chronic prescription medication use & 2,333 & 14.8 & 14.2 & 15.3 \\
\hline
\end{tabular}

*: Prevalence $(\%)$ in runners 
Table 5. The prevalence of more specific medication use during a race in all the runners (\% runners; $95 \% \mathrm{Cl})(\mathrm{n}=15778)$.

\begin{tabular}{|c|c|c|c|c|c|}
\hline \multirow[t]{2}{*}{ Medication group } & $\begin{array}{c}\text { Specific } \\
\text { medication }\end{array}$ & \multicolumn{4}{|c|}{ All runners $(n=15778)$} \\
\hline & & $\mathrm{n}$ & $\begin{array}{l}\% \text { of all } \\
\text { runners }\end{array}$ & \multicolumn{2}{|c|}{$95 \% \mathrm{Cl}$} \\
\hline \multicolumn{6}{|l|}{ One week before a race } \\
\hline \multirow[t]{3}{*}{ Analgesics } & Paracetamol & 621 & 3,9 & 3.6 & 4.2 \\
\hline & Codeine & 67 & 0,4 & 0.3 & 0.5 \\
\hline & $\begin{array}{l}\text { Other } \\
\text { analgesics }\end{array}$ & 212 & 1,3 & 1.2 & 1.5 \\
\hline \multirow{5}{*}{$\begin{array}{l}\text { Anti -inflammatory } \\
\text { medication }\end{array}$} & & 2,022 & 12,8 & 12.3 & 13.3 \\
\hline & NSAIDs & 1,442 & 9,1 & 8.7 & 9.6 \\
\hline & $\begin{array}{l}\text { Cortisone } \\
\text { (any) }\end{array}$ & 255 & 1,6 & 1.4 & 1.8 \\
\hline & Cortisone pills & 43 & 0,3 & 0.2 & 0.4 \\
\hline & $\begin{array}{l}\text { Cortisone } \\
\text { injection }\end{array}$ & 228 & 1,5 & 1.3 & 1.6 \\
\hline \multicolumn{6}{|l|}{ During a race } \\
\hline \multirow[t]{3}{*}{ Analgesics } & Paracetamol & 484 & 3,1 & 2.8 & 3.3 \\
\hline & Codeine & 46 & 0,3 & 0.2 & 0.4 \\
\hline & $\begin{array}{l}\text { Other pain } \\
\text { killers }\end{array}$ & 278 & 1.8 & 1.6 & 2.0 \\
\hline \multirow{5}{*}{$\begin{array}{l}\text { Any anti- inflammatory } \\
\text { medication }\end{array}$} & & 1,227 & 7,8 & 7.4 & 8.2 \\
\hline & NSAIDs & 776 & 4,9 & 4.6 & 5.3 \\
\hline & $\begin{array}{l}\text { Cortisone } \\
\text { (any) }\end{array}$ & 41 & 0,3 & 0.2 & 0.3 \\
\hline & Cortisone pills & 14 & 0,1 & 0.0 & 0.1 \\
\hline & $\begin{array}{l}\text { Cortisone } \\
\text { injection }\end{array}$ & 29 & 0,2 & 0.1 & 0.3 \\
\hline
\end{tabular}

NSAIDs: Non-steroidal anti-inflammatory drugs 
Table 6. Runners with specific criteria, expressed as a \% (95\% Cl) of all runners ( $n=4941$ ) that were identified by the current ESC/EACPR guidelines (Sections 1 and 2) to undergo a pre-exercise medical assessment.

\begin{tabular}{|c|c|c|c|c|c|}
\hline \multirow[t]{2}{*}{$\begin{array}{l}\text { Sections/main categories } \\
\text { per section }\end{array}$} & \multirow[t]{2}{*}{ Specific criteria } & \multicolumn{4}{|c|}{$\begin{array}{l}\text { All identified runners } \\
(n=4,941)\end{array}$} \\
\hline & & $\mathrm{N}$ & $\%$ & $95 \%$ & $6 \mathrm{Cl}$ \\
\hline \multicolumn{6}{|c|}{ Section 1 - Medical conditions } \\
\hline \multirow[t]{8}{*}{ History } & Heart attack & 50 & 1.0 & 0.7 & 1.3 \\
\hline & Heart surgery & 19 & 0.4 & 0.2 & 0.6 \\
\hline & Coronary angioplasty & 40 & 0.8 & 0.6 & 1.1 \\
\hline & $\begin{array}{l}\text { Heart rhythm } \\
\text { disturbance a }\end{array}$ & 74 & 1.5 & 1.2 & 1.8 \\
\hline & Heart valve disease & 64 & 1.3 & 1.0 & 1.6 \\
\hline & Heart failure & 1 & 0.0 & 0.0 & 0.1 \\
\hline & Cardiac transplantation & - & - & - & - \\
\hline & $\begin{array}{l}\text { Congenital heart } \\
\text { disease }\end{array}$ & 11 & 0.2 & 0.1 & 0.4 \\
\hline \multirow[t]{4}{*}{ Symptoms/medication use } & $\begin{array}{l}\text { Chest pain with } \\
\text { exertion }\end{array}$ & 31 & 0.6 & 0.4 & 0.9 \\
\hline & $\begin{array}{l}\text { Unreasonable } \\
\text { breathlessness }\end{array}$ & 48 & 1.0 & 0.7 & 1.3 \\
\hline & Dizziness or fainting & 61 & 1.2 & 0.9 & 1.5 \\
\hline & Heart medication ${ }^{2}$ & - & - & - & - \\
\hline \multirow[t]{4}{*}{ Other health issues } & $\begin{array}{l}\text { Musculoskeletal } \\
\text { conditions }\end{array}$ & 2,710 & 54.9 & 53.5 & 56.2 \\
\hline & Concerns about exercise & - & - & - & - \\
\hline & $\begin{array}{l}\text { Prescription } \\
\text { medications }\end{array}$ & 2,333 & 47.2 & 45.8 & 48.6 \\
\hline & Pregnant ${ }^{3}$ & - & - & - & - \\
\hline \multicolumn{6}{|l|}{ Section 2 - Risk factors } \\
\hline \multirow[t]{9}{*}{ CVD Risk factors } & $\begin{array}{c}\text { Male }>45 \text { years } \\
\quad(n=1152)\end{array}$ & 1,152 & 23.3 & 22.1 & 24.5 \\
\hline & $\begin{array}{l}\text { Female }>55 \text { years }{ }^{4} \\
\quad(n=142)\end{array}$ & 142 & 2.9 & 2.4 & 3.3 \\
\hline & Smoking & 218 & 4.4 & 3.8 & 5.0 \\
\hline & High blood pressure ${ }^{5}$ & 641 & 13.0 & 12.0 & 13.9 \\
\hline & High cholesterol ${ }^{6}$ & 760 & 15.4 & 14.4 & 16.4 \\
\hline & $\begin{array}{l}\text { Diabetic/medication for } \\
\text { diabetes }\end{array}$ & 140 & 2.8 & 2.4 & 3.3 \\
\hline & Family history of CVD & 514 & 10.4 & 9.6 & 11.3 \\
\hline & Physical inactivity ${ }^{7}$ & - & - & - & - \\
\hline & Overweight $^{8}$ & 156 & 3.2 & 2.7 & 3.6 \\
\hline
\end{tabular}

a: Includes pacemaker/implantable defibrillator/rhythm disturbance; ${ }^{2}$ : No specific question on heart medication; ${ }^{3}$ : No question on pregnancy; ${ }^{4}$ : No specific question about hysterectomy or being post-menopausal; ${ }^{5}$ : No specific question on unknown blood pressure and blood pressure medication; ${ }^{6}$ : No specific question about unknown cholesterol; ${ }^{7}$ : No question on physical inactivity - all participants entered a distance running event; ${ }^{8}$ : Question was on 'obesity' and not specific to $>20$ pounds overweight

*: Significantly different between $56 \mathrm{~km}$ and $21.1 \mathrm{~km}$ runners 
In how many munners did the pre-participation "selfassessment of risk" medical screening (using the ESC/ EACPR guidelines) identify the need to undergo a full pre-participation medical assessment prior to muning?

The pre-participation "self assessment of risk" screening identified 4,941 runners (31.3\%; 95\% CI 30.6-32.0) that would need to undergo a full pre-participation medical assessment prior to running, if the current ESC/EACPR pre-participation screening guidelines are applied [27,28]. Of these runners, 16.8\% ( $\mathrm{n}=2,657)$ runners should undergo medical evaluation for suspected cardiac disease based on the questionnaire results: $3.4 \%(n=538)$ reporting existing CVD (very high risk) and $13.4 \%(n=2,119)$ reporting multiple CVD risk factors (high risk). The specific criteria (by Sections 1 and 2 of the AHA/ ACSM screening recommendations in the ESC/EACPR guidelines), that were responsible for the recommendation to undergo a full medical assessment (expressed as a $\%$ of the 4,941 runners that were identified), are depicted in Table 6.

The main criterion that would lead to the recommendation for referral to undergo a full medical assessment before competing was a self reported musculoskeletal condition (54.9\% of the runners that were identified). The use of prescription medication and the gender/age criterion (male gender: over 45 years) followed as criteria for referral. Risk factors associated with CVD, including a high serum cholesterol concentration, high blood pressure, and diabetes mellitus were also common criteria for referral.

Of the 4,941 runners that were identified through the screening process, $22 \%$ were identified because of CVD risk factors, $23 \%$ were identified because of other medical conditions plus one other risk factor for CVD, and another 55\% were identified because of other medical conditions, with no CVD risk factors. Almost half of the athletes with any one CVD risk factor were not identified for screening $(1,996 /$ 4,244).

We also noted that $2 \%$ more $56 \mathrm{~km}$ runners $(\mathrm{n}=1,630,32.7 \%)$ were identified to undergo screening by the guidelines, compared to $21 \mathrm{~km}$ runners $(\mathrm{n}=3,311,30.7 \%)$, and $1.4 \%$ more male runners $(n=2847,31.9 \%)$ were identified compared to female runners $(n=2,094$, $30.5 \%)$.

\section{Discussion}

The main finding of this study was that an online pre-participation "self-assessment of risk," as currently recommended by European guidelines could be implemented successfully during pre-race registration in a community-based mass sports participation (distance running) event. In $>15,000$ recreational distance runners, the pre-race screening tool identified that over 30\% of entrants for this event would, according to current European guidelines, require referral for a full medical assessment prior to participation in the distance races (moderate-to-high intensity exercise). Additional findings of this study were as follows: 
(a) 2.3\% runners reported suffering from existing CVD, 1.8\% reported current symptoms suggestive of existing CVD, and $16.1 \%$ reported at least one risk factor for CVD; (b) the prevalence of other existing chronic diseases, by organ systems was as follows: respiratory (13.1\%), gastro-intestinal (4.3\%), nervous system (3.8\%), metabolic or endocrine system (3.5\%); (c) 13.9\% runners reported suffering from allergic disease; (d) 14.8\% runners reported using chronic medication; (e) $15.6 \%$ of runners reported using medication to treat injuries 7 days before or during races; and (f) 1.4\% of all runners reported a past history of collapse during a race.

International pre-exercise screening recommendations in leisure athletes [25,27,28] are currently not applied at community-based mass participation events and there are few data that these guidelines are indeed appropriate for pre-event medical screening of leisure athletes. To our knowledge, this is the first study to report pre-participation screening data to determine the risk profile of participants in such a community-based mass participation distance running event and we cannot compare our main finding to any other similar population of recreational athletes. We do note that distance running events (21.1 km and ultra-marathon), such as the ones described in our study, are hosted all over the world, are becoming increasingly popular, and that participation in these events is encouraged as part of promoting a healthy active lifestyle. As far as we are aware, in most cases, these events are also openentry and attract runners from all age groups. This can result in an increased proportion of runners that require no pre-entry qualifying times and enter races where there are no preevent medical screening criteria.

Data reported on medical complications of participants during such events are largely limited to retrospective analysis of the incidence of sudden cardiac arrest and death. However, cardiac arrest and sudden death only represent the most severe medical complications during such events. There are few published data regarding other medical complications that do not necessarily lead to cardiac arrest, but are still regarded as potentially serious and even lifethreatening medical complications and all medical complications during these events [5,34].

We show that the presence of musculoskeletal complaints (54.9\% of runners) was the main criteria identified by the current European guidelines [27,28], for recommending consulting a physician before exercise, and that $32.34 \%$ of the runners that would be referred for a medical assessment, reported musculoskeletal complaints as their only criteria for referral. Distance running is associated with a high prevalence of musculoskeletal complaints; therefore, we question the value of including the history of a musculoskeletal problem as part of a screening tool for this population as this would require referral of a large number of runners for pre-participation medical examinations.

The use of prescription medication (47.2\% of runners) was the next most common criteria identified by the current European guidelines [27,28], for recommending consulting a physician before exercise. The potential risk of a medical complication during exercise, as a result of prescription medication, can vary greatly and is related to the underlying medical condition is for which the medication is prescribed, and the side 
effect profile of the medication. Some pharmacological agents may be associated with an increased risk of developing cardiac arrhythmias [35-38], renal complications including acute renal failure [39], rhabdomyolysis [40,41], gastrointestinal bleeding [42-44], and risk of tendon injuries including acute tendon rupture $[45,46]$. We recommend that a screening tool could be modified to include more specific information about classes of medication that may be associated with increased risk of medical complications during exercise.

In our study, we did explore the prevalence of underlying chronic medical conditions in this population of runners. We identified that $2.3 \%$ of all runners reported known existing cardiovascular disease (CVD) and the most common CVD's were coronary artery disease (0.5\%), and arrhythmia (0.4\%). A history of a heart murmur was reported by $0.6 \%$ runners, but this may not necessarily indicate CVD. Furthermore, 1.8\% runners reported symptoms that may be suggestive of CVD, but we acknowledge that some of the symptoms, such as painful calves when walking and chronic cough, are not specific and may not indicate underlying CVD.

As is recommended by international guidelines [25,28], we would strongly recommend that runners with existing CVD and those with symptoms suggestive of CVD undergo a full medical assessment before participating in moderate- to high-intensity exercise such as distance running events, because they represent a "very high risk" group for developing potentially serious acute cardiovascular complications during a distance-running event.

Our data showed that $16.1 \%$ of runners reported at least risk factor for CVD, with 13.4\% reporting more than one risk factor. The most common specific risk factors for CVD were high blood cholesterol concentration (5.8\%), high blood pressure (4.4\%), and a family history of heart disease (4.4\%). In addition, over $15 \%$ of the runners were males $>45$ years. According to the European guidelines [27,28], older runners (males $\geq 45$ years; females $\geq 55$ years) with one or more risk factors for CVD, and runners of younger age with two or more risk factors for CVD require medical assessment before engaging in moderate- to high-intensity exercise such as distance running. The recently revised recommendations by the ACSM excluded risk factors for CVD as criteria for a pre-exercise medical assessment [25]. However, in our experience at the Two Oceans races, runners who died or suffered from serious life threatening medical complications were mostly in this 'high risk' group. Therefore, we would recommend that runners with $\geq 1$ risk factor for CVD undergo a full medical assessment before participating in these moderate- to high- intensity exercise events, until there is stronger evidence that the risk of an acute medical complication in runners falling into this category is not increased.

In our population of runners, the prevalence of existing disease in other organ systems varied between $1.9 \%$ (cancer) to $13.1 \%$ (respiratory disease). We recognize that there is a variable risk of a medical complication in this group of runners and the risk is likely based on many factors such as: (a) the stage of the disease including the presence 
or absence of multi-organ complications of a disease, (b) the level of control of the disease, (c) side effects of any treatment (e.g. medication, radiation therapy, previous surgery), and (d) the effect of significant environmental conditions or physiological stress such as moderate-to-high intensity exercise in "unmasking" disease exacerbation or any of the above (a to c). We recognize the complexity and individual variability of determining the specific risk of a medical complication during exercise in the presence of an underlying chronic disease. We suggest that underlying chronic disease constitutes at least an "intermediate risk" for medical complications during exercise and should be included in any pre-race screening program for leisure athletes, and that these runners undergo a full medical assessment before participating in these events.

The finding that $15.6 \%$ of runners reported ingestion of pharmacological agents, mainly anti-inflammatory medication (7.8\%), and more specifically NSAIDs (4.9\%), in the 7 days before or during races is of concern. The association between NSAID use and medical complications is known, specifically the risk of acute renal [39] and gastro-intestinal complications [42-44]. We therefore suggest that the use of these medications during racing also constitutes an "intermediate risk" for medical complications during exercise and should be included in any pre-race screening program for recreational athletes.

Finally, in our study, 1.4\% runners reported a past history of collapse during exercise. It is well-established that a history of collapse during exercise can be indicative of a more serious medical complication [47-49], therefore we suggest that this constitutes an "intermediate risk" and this information should be included in any pre-race screening program for recreational athletes.

The main strengths of this study are that it is, as far as we are aware, the first study to report on the feasibility and outcomes of an online pre-race medical screening tool for a large population of recreational runners participating in a mass community based distance running event. Furthermore, we report the data on a large sample size that is a representative sample (age, gender, and race type) of race entrants with a response rate of $62.8 \%$.

Limitations of this study are firstly that we note that older males were under-represented in the consent sample and this is a limitation since the proportion of athletes identified for screening could then be under-reported in this study. A further limitation is that data are self-reported and that not all runners may have fully understood the questions asked or may have under-appreciated the importance of the request for accuracy in the answers. Therefore, again the data presented in this article may indeed be under-reported. If this is in fact the case, the risk profile of runners in this the sample may under-represent the actual risk profile. Finally, although runners in the higher risk categories (existing CVD and those with risk factors for CVD) were advised (by email communication) to undergo medical evaluation, we do not report data on how many actually took up this advice and how many developed any medical complications. In future studies, we will address this limitation. 


\section{Opinion and recommendations}

We describe the development and implementation of a relatively low-cost pre-race screening tool to determine the "self-assessment of risk" of a medical complication during exercise in a community-based mass participation distance running event. We show that by using current screening guidelines, $>30 \%$ of all runners entering for these events would require a full medical assessment, where a history of a musculoskeletal complaint and the use of prescription medication were the main criteria in the existing guidelines that triggered a referral to undergo a full medical assessment. We suggest a revision of the screening guidelines triggering a full medical assessment and propose risk stratification and educational intervention (Table 7) as follows: (1) excluding the question on musculoskeletal complaints from triggering a full medical assessment, (2) including a question on prescription medication but refining it for specific classes of drugs that could potentially increase the risk of medical complications during exercise, and (3) including questions on other chronic diseases with organ system and disease specific recommendations on full medical assessment. Finally, future studies, should determine the feasibility and implementation of such a screening and educational intervention program on reducing medical complications during these events. This pre-race screening program is ongoing and has already been implemented in other large endurance events. In future, we will continue to report on the relationship of the risk profile of endurance athletes ("very high risk," "high risk," and "intermediate risk" groups) and the actual risk of medical complications during endurance events. These data will assist in decision-making regarding pre-participation screening guidelines for these leisure distance-running athletes.

Declaration of Helsinki: Permission to analyse the medical histories of the study subjects was obtained from the Research Ethics Committee of the University of Cape Town (REC 009/ 2011) (REC 030/2013) and the Research Ethics Committee of the University of Pretoria (REC 433/2015). This study complied with the Declaration of Helsinki's ethical principles for conducting medical research involving human participants.

\section{Funding}

The study was partially funded by a research grant from the International Olympic Committee (IOC) Research Centre (South Africa) at the University of Pretoria.

\section{Declaration of interest}

The authors have no relevant affiliations or financial involvement with any organization or entity with a financial interest in or financial conflict with the subject matter or materials discussed in the manuscript. This includes employment, consultancies, honoraria, stock ownership or options, expert testimony, grants or patents received or pending, or royalties. Peer reviewers on this manuscript have no relevant financial relationships to disclose.

\section{Data sharing statement}

No additional data are available 


\section{Declaration of interest}

No potential conflict of interest was reported by the authors.

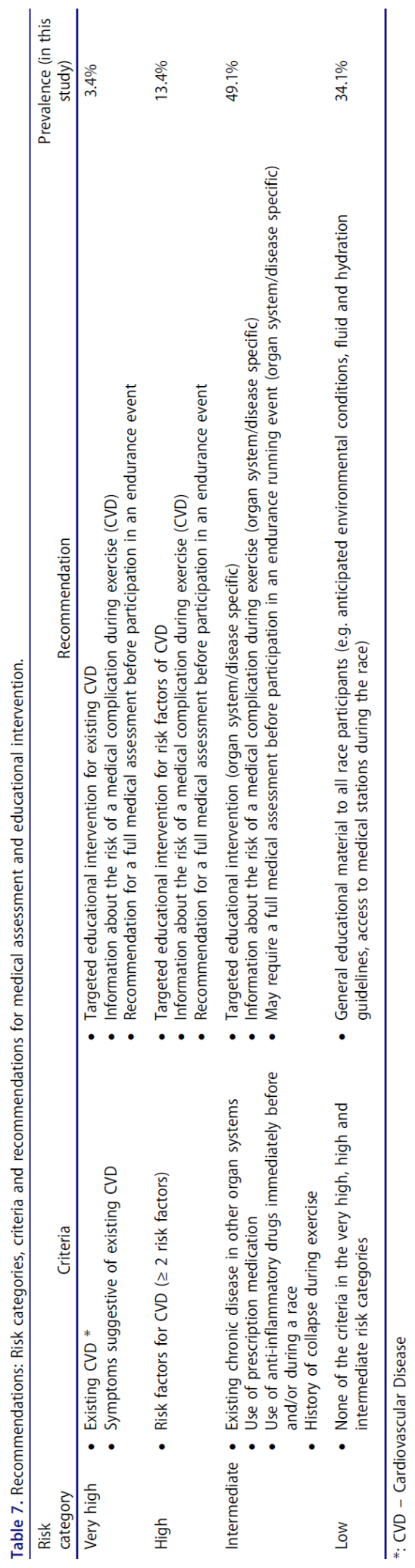




\section{References}

1. Haskell WL, Lee IM, Pate RR, et al. Physical activity and public health: updated recommendation for adults from the American College of Sports Medicine and the American Heart Association [Congresses]. Circulation. 2007 Aug 28;116(9):1081-1093. PubMed PMID: 17671237; eng.

2. Khan KM, Thompson AM, Blair SN, et al. Sport and exercise as contributors to the health of nations. Lancet. 2012 Jul 7;380 (9836):59-64. PubMed PMID: 22770457.

3. Chugh SS, Weiss JB. Sudden cardiac death in the older athlete. J Am Coll Cardiol. 2015 Feb 10;65(5):493-502. PubMed PMID: 25660928.

4. Sanchez LD, Corwell B, Berkoff D. Medical problems of marathon runners. Am J EmergMed. 2006;24(5):608-615.

5. Schwabe K, Schwellnus M, Derman W, et al. Medical complications and deaths in 21 and $56 \mathrm{~km}$ road race runners: a 4-year prospective study in 65865 runners SAFER study I. Br J Sports Med. 2014 Jun;48(11):912-918. PubMed PMID: 24735839.

6. Schwellnus MP. Premarathon evaluations: is There a role for runner prerace medical screening and education to reduce the risk of medical complications? Curr Sports Med Rep. 2017 May/Jun;16 (3):129-136. PubMed PMID: 28498219.

7. Siegel AJ. Pheidippides redux: reducing risk for acute cardiac events during marathon running. Am J Med. 2012 Jul;125(7):630- 635. PubMed PMID: 22608535 .

8. Day SM, Thompson PD. Cardiac risks associated with marathon running. Sports Health. 2010 Jul;2(4):301-306. PubMed PMID: 23015951; PubMed Central PMCID: PMC3445091. eng.

9. Thompson PD, Franklin BA, Balady GJ, et al. Exercise and acute cardiovascular events placing the risks into perspective: a scientific statement from the American Heart Association Council on Nutrition, Physical Activity, and Metabolism and the Council on Clinical Cardiology. Circulation. 2007 May 1;115(17):2358-2368. PubMed PMID: 17468391.

10. Gerardin B, Collet JP, Mustafic H, et al. Registry on acute cardiovascular events during endurance running races: the prospective RACE Paris registry. Eur Heart J. 2016 Aug 21;37(32):2531-2541. PubMed PMID: 2671568

11. Roberts WO, Roberts DM, Lunos S. Marathon related cardiac arrest risk differences in men and women. Br J Sports Med. 2013 Feb;47 (3):168-171. PubMed PMID: 22736205; eng.

12. Webner D, DuPrey KM, Drezner JA, et al. Sudden cardiac arrest and death in United States marathons [Research support, Non-U.S. Gov't]. Med Sci Sports Exerc. 2012 Oct;44(10):1843-1845. PubMed PMID: 22525769; eng.

13. Mathews SC, Narotsky DL, Bernholt DL, et al. Mortality among marathon runners in the United States, 2000-2009. Am J Sports Med. 2012 Jul;4O(7):1495-1500. PubMed PMID: 22562789. 
14. Kim JH, Malhotra R, Chiampas G, et al. Cardiac arrest during long-distance running races. N Engl J Med. 2012 Jan 12;366(2):130-140. PubMed PMID: 22236223; eng.

15. Cohen SI, Ellis ER. Death and near death from cardiac arrest during the Boston Marathon [Case reports, Research support, Non-U.S. Gov't]. Pacing Clin Electrophysiol. 2012 Feb;35(2):241-244. PubMed PMID: 22040232; eng.

16. Finn SE, Coviello J. Myocardial infarction \& sudden death in recreational master marathon runners. Nurse Pract. 2011 Feb;36(2):48-53. PubMed PMID: 21245724 .

17. Thunenkotter T, Schmied C, Dvorak J, et al. Benefits and limitations of cardiovascular pre-competition screening in international football. Clin Res Cardiol. 2010 Jan;99(1):29-35. PubMed PMID: 19756813.

18. Mont L, Pelliccia A, Sharma S, et al. Pre-participation cardiovascular evaluation for athletic participants to prevent sudden death: position paper from the EHRA and the EACPR, branches of the ESC. Endorsed by APHRS, HRS, and SOLAECE. Eur J Prev Cardiol. 2017 Jan;24(1):41-69. PubMed PMID: 27815537. 19. Ljungqvist A, Jenoure P, Engebretsen L, et al. The International Olympic Committee (IOC) consensus statement on periodic health evaluation of elite athletes. $\mathrm{Br} \mathrm{J}$ Sports Med. 2009 March;43(9):631-643. .

20. Drezner JA, O'Connor FG, Harmon KG, et al. AMSSM position statement on cardiovascular preparticipation screening in athletes: current evidence, knowledge gaps, recommendations and future directions. $\mathrm{Br}$ J Sports Med. 2017 Feb;51(3):153-167. PubMed PMID: 27660369.

21. Drezner JA, Harmon KG, Asif IM, et al. Why cardiovascular screening in young athletes can save lives: a critical review. $\mathrm{Br} \quad \mathrm{J}$ Sports Med. 2016 Nov;50(22):1376-1378. PubMed PMID: 27418320.

22. Chatard JC, Mujika I, Goiriena JJ, et al. Screening young athletes for prevention of sudden cardiac death: practical recommendations for sports physicians. Scand J Med Sci Sports. 2016 Apr;26(4):362-374. PubMed PMID: 26432052.

23. Aagaard P, Sahlen A, Bergfeldt L, et al. Preparticipation evaluation of novice, middle-age, long-distance runners. Med Sci Sports Exerc. 2013 Jan;45(1):130137. PubMed PMID: 22895374.

24. Maron BJ, Araujo CG, Thompson PD, et al. Recommendations for preparticipation screening and the assessment of cardiovascular disease in masters athletes: an advisory for healthcare professionals from the working groups of the World Heart Federation, the International Federation of Sports Medicine, and the American Heart Association Committee on Exercise, Cardiac Rehabilitation, and Prevention. Circulation. 2001 Jan 16;103(2):327-334. PubMed PMID: 11208698.

25. Riebe D, Franklin BA, Thompson PD, et al. Updating ACSM's recommendations for exercise preparticipation health screening. Med Sci Sports Exerc. 2015 Nov;47(11):2473-2479. PubMed PMID: 26473759.

26. Bredin SS, Gledhill N, Jamnik VK, et al. PAR-Q+ and ePARmed-X+: new risk stratification and physical activity clearance strategy for physicians and patients 
alike. Can Fam Physician. 2013 Mar;59(3):273-277. PubMed PMID: 23486800; PubMed Central PMCID: PMC3596208.

27. Corrado D, Schmied C, Basso C, et al. Risk of sports: do we need a preparticipation screening for competitive and leisure athletes? Eur Heart J. 2011 Apr;32(8):934-944. PubMed PMID: 21278396.

28. Borjesson M, Urhausen A, Kouidi E, et al. Cardiovascular evaluation of middleaged/senior individuals engaged in leisure-time sport activities: position stand from the sections of exercise physiology and sports cardiology of the European Association of Cardiovascular Prevention and Rehabilitation. Eur $\mathrm{J}$ Cardiovasc Prev Rehabil. 2011 Jun;18(3):446-458. PubMed PMID: 21450560; eng.

29. Balady GJ, Chaitman B, Driscoll D, et al. Recommendations for cardiovascular screening, staffing, and emergency policies at health/fitness facilities. Circulation. 1998 Jun 9;97(22):2283-2293. PubMed PMID: 9631884; eng.

30. Whitfield GP, Pettee Gabriel KK, Rahbar MH, et al. Application of the American Heart Association/American College of Sports Medicine Adult Preparticipation Screening Checklist to a nationally representative sample of US adults aged $\geq 40$ years from the National Health and Nutrition Examination Survey 2001 to 2004. Circulation. 2014 Mar 11;129(10):1113-1120. PubMed PMID: 24421370; PubMed Central PMCID: PMCPMC4094111.

31. Schwellnus M, Derman W. The quest to reduce the risk of adverse medical events in exercising individuals: introducing the SAFER (Strategies to reduce adverse medical events for the exerciseR) studies. Br J Sports Med. 2014 Jun;48(11):869870. PubMed PMID: 24815926.

32. Schwabe K, Schwellnus MP, Derman W, et al. Older females are at higher risk for medical complications during $21 \mathrm{~km}$ road race running: a prospective study in 39 511 race starters - SAFER study III. Br J Sports Med. 2014 Jun;48(11):891-897. PubMed PMID: 24815927.

33. Schwabe K, Schwellnus MP, Derman W, et al. Less experience and running pace are potential risk factors for medical complications during a $56 \mathrm{~km}$ road running race: a prospective study in 26354 race starters - SAFER study II. Br J Sports Med. 2014 Jun;48(11):905- 911. PubMed PMID: 24815928.

34. Roberts WO. A 12-yr profile of medical injury and illness for the Twin Cities Marathon. MedSciSports Exerc. 2000;32(9):1549-1555.

35. Behr ER, Roden D. Drug-induced arrhythmia: pharmacogenomic prescribing? Eur Heart J. 2013 Jan;34(2):89-95. PubMed PMID: 23091201; PubMed Central PMCID: PMCPMC3538275.

36. Tamargo J, Caballero R, Delpon E. Drug-induced atrial fibrillation. Expert Opin Drug Saf. 2012 Jul;11(4):615-634. PubMed PMID: 22724662.

37. Granier M, Massin F, Pasquie JL. Pro- and anti-arrhythmic effects of antiinflammatory drugs. Antiinflamm Antiallergy Agents Med Chem. 2013;12(1): 8393. PubMed PMID: 23286288.

38. Evans B, Cox A, Nicol E, et al. Drug-associated arrhythmia in the military patient. J R Army Med Corps. 2015 Sep;161(3):253-258. PubMed PMID: 26272949. 
39. Lange ML, Skansing TB. [Acute renal failure after participation in high endurance sport]. Ugeskr Laeger. 2016 Jan 18;178(3):2-3. PubMed PMID: 26815586.

40.Szczepanik ME, Heled Y, Capacchione J, et al. Exertional rhabdomyolysis: identification and evaluation of the athlete at risk for recurrence. Curr Sports Med Rep. 2014 Mar-Apr;13(2):113-119. PubMed PMID: 24614425.

41. Sandhu RS, Como JJ, Scalea TS, et al. Renal failure and exercise-induced rhabdomyolysis in patients taking performance-enhancing compounds. J Trauma. 2002 Oct;53(4):761-3; discussion 763-4. PubMed PMID: 12394880. 42. Alaranta A, Alaranta H, Helenius I. Use of prescription drugs in athletes. Sports Med. 2008;38(6): 449-463. PubMed PMID: 18489193.

43. Waterman JJ, Kapur R. Upper gastrointestinal issues in athletes. Curr Sports Med Rep. 2012 Mar-Apr;11(2):99-104. PubMed PMID: 22410703.

44. Shoor S. Athletes, nonsteroidal anti-inflammatory drugs, coxibs, and the gastrointestinal tract. CurrSports MedRep. 2002;1(2):107-115.

45. Melhus A. Fluoroquinolones and tendon disorders. Expert Opin Drug Saf. 2005 Mar;4(2):299-309. PubMed PMID: 15794721.

46.van der Linden PD, Nab HW, Simonian S, et al. Fluoroquinolone use and the change in incidence of tendon ruptures in the Netherlands. PharmWorld Sci. 2001;23(3):89-92.

47. Roberts WO. Exercise-associated collapse care matrix in the marathon. Sports Med. 2007;37(4-5):431-433.

48. Asplund CA, O'Connor FG, Noakes TD. Exercise-associated collapse: an evidence-based review and primer for clinicians. Br J Sports Med. 2011 Nov;45(14):1157-1162. PubMed PMID: 21948122.

49. Speedy DB, Noakes TD, Holtzhausen LM. Exercise-associated collapse: postural hypotension, or something deadlier? Phys Sportsmed. 2003 Mar;31(3):2329. PubMed PMID: 20086459. 